\title{
A utilização da metododologia do discurso do sujeito coletivo na avaliação qualitativa dos cursos de especialização "Capacitação $e$ Desenvolvimento de Recursos Humanos em Saúde-CADRHU", São Paulo - 2002
}

Discourse of the collective subject in the qualitative evaluation of pos-graduation "lato sensu" Courses: Training and Development of Health Manpower - CADRHU, São Paulo - 2002

\author{
Ana Maria Cavalcanti Lefevre \\ Pesquisadora do Centro de Contorle de Doenças da Prefeitura de \\ Município de São Paulo, Doutora pela Faculdade de Saúde Pú- \\ blica da Universidade de São Paulo e Comissionada na Faculda- \\ de de Saúde Pública da Universidade de São Paulo \\ E-mail: alefevreœusp.br \\ Maria Fazanelli Crestana- \\ Diretora Técnica do Serviço de Biblioteca e Documentação da \\ Faculdade de Medicina da Universidade de São Paulo e Doutoran- \\ da na Faculdade de Saúde Pública da Universidade de São Paulo \\ E-mail: crestanaœbiblioteca.fm.usp. br

\section{Vitória Kedy Cornetta} \\ Professora Livre-Docente da Faculdade de Saúde Pública da Uni- \\ versidade de São Paulo \\ E-mail: vkvfspœfsp.usp.br
}

\section{Resumo}

O presente artigo traz uma avaliação da satisfação dos alunos dos cursos de especialização "Capacitação e Desenvolvimento de Recursos Humanos em SaúdeCADRHU-2002", que foram oferecidos pelo convênio firmado entre a Secretaria de Estado da Saúde e Faculdade de Saúde Pública/USP. Para tanto utiliza a técnica do Discurso do Sujeito Coletivo (Lefèvre e Lefèvre, 2000) que é uma metodologia de organização e tabulação de dados qualitativos de natureza verbal, obtidos de depoimentos. Consiste em apresentar os resultados sob a forma de um ou vários discursos-síntese, escritos na primeira pessoa do singular, expediente que visa expressar o pensamento de uma coletividade, como se esta coletividade fosse o emissor de um discurso. De uma maneira geral, os alunos avaliaram positivamente a metodologia do CADRHU como favorecedora da participação, da troca de experiências, da aprendizagem e do desenvolvimento do pensamento crítico.

Descritores: Recursos humanos em saúde. Pesquisa qualitativa. Educação em Saúde Pública. Educação profissional em saúde. 


\section{Summary}

This article makes an the evaluation of the satisfaction, among students of the course: "Training and development of manpower in Health " - CADRHU 2002", that was offered by the Health State Secretary and Public Health School/USP.

In order to do that, the authors used the technical devices of the Discourse of the Collective Subject (Lefèvre e Lefèvre, 2000), a methodology for the organization and computerized tabulation of qualitative data obtained from interviews. Basically using the theory of Social Representation, the proposal consists in presenting the results in many synthesis-speeches, written in the singular first person of the singular, in order to express the thought of the community, as if this community were a speech subject.

In a general way, the students made a positive evaluation of the CADRHU methodology as a support for the participation, as well as for exchanging learning experiences and for the development of critical thought.

Descriptors: Health Manpower. Qualitative Research. Public Health Education. Health professional education.

\section{Introdução}

De importância reconhecida em qualquer ramo de atividade produtiva, a formação de recursos humanos na saúde ganha dimensão particular e significativa, pela natureza do trabalho em saúde.

As instituições formadoras de recursos humanos em saúde têm despendido esforços importantes na busca de alternativas à sua ação educativa. Esses esforços se refletem no plano do ensino, na produção do conhecimento e também na ação política de seus quadros técnicos, políticos e dirigentes. Esse movimento tem proporcionado a formulação de programas de formação que influenciam e são influenciados pela própria história da construção do campo (Cornetta, 1997). Seu processo e as práticas de seus agentes definem referências e saberes fundamentais para os processos de capacitação e desenvolvimento de quadros para o setor.

Visando melhor capacitação e desenvolvimento dos quadros de técnicos em recursos humanos em saúde, durante o período de 1991 e 1997, mediante promoção conjunta do Ministério da Saúde e da Representação da Organização Pan-Americana da SaúdeOPAS, no Brasil, grupos de trabalho trataram de sistematizar as experiências acumuladas, produzindo versões revisadas do currículo do curso "Capacitação em Desenvolvimento de Recursos Humanos de Saúde- CADRHU" que havia tido início em 1986 (Ministério da Saúde \& OPS, 1999).

Em São Paulo foi firmado um convênio com o Ministério da Saúde, Secretaria de Estado da Saúde e Faculdade de Saúde Pública da Universidade de São Paulo, cujo propósito foi o de contribuir para a modernização e melhoria dos processos institucionais da área de saúde e recursos humanos, no âmbito do serviço público de saúde, através da capacitação de seus quadros político-técnico administrativos.

O convênio tinha como finalidade a realização de seis (6) cursos de especialização, com carga horária de 36o horas/aula cada, divididas em três (3) módulos. A clientela foi composta de 260 funcionários da Secretaria, de nível superior, que ocupavam posição de assessoramento, coordenação ou gerência de recursos humanos.

Ao tratar dos módulos dos cursos de especialização do CADRHU é necessário o resgate do que signifi- 
ca a proposta do currículo integrado, de acordo com Davini (1999) “... um plano pedagógico e sua correspondente organização institucional que articula dinamicamente trabalho e ensino, prática e teoria, ensino e comunidade. As relações entre trabalho e ensino, entre os problemas e suas hipóteses de solução devem ter sempre, como pano de fundo, as características sócio-culturais do meio em que este processo se desenvolve."

Por sua vez, a avaliação do CADRHU, ainda segundo a mesma autora, tem função especial dentro do currículo integrado pois “... se fundamenta no princípio de que a aprendizagem não é alcançada de forma instantânea nem por domínio de informações técnicas, pelo contrário, requer um processo de aproximações sucessivas e cada vez mais amplas e integradas, de modo que o educando, a partir da reflexão sobre suas experiências e percepções iniciais, observe, reelabore e sistematize seu conhecimento do objeto em estudo" (Davini, 1999).

Neste sentido a avaliação que se faça sobre o CADRHU, diz respeito tanto aos objetivos e eficácia do programa de ensino em si, como do trabalho desenvolvido pelos supervisores, que ministraram os cursos.

As avaliações de corte qualitativo tem uma dimensão claramente simbólica, que no caso, refere-se aos esquemas sócio-cognitivos (Bourdieu, 1990) subjacentes à percepção dos alunos sobre os cursos. Com efeito, uma avaliação ideal da percepção dos alunos sobre tais cursos deveria ter como objetivo maior analisar como estes alunos sentem e descrevem sua experiência com os diferentes aspectos do curso. A avaliação tradicional de cursos, de corte quantitativo, desta percepção, na qual se pede que o pesquisado opte pelas alternativas, apresentadas sob a forma de adjetivos valorativos como: excelente, bom, regular, péssimo, etc., é claramente insuficiente com vistas a fornecer informações aos proponentes dos cursos . Mais especificamente corre-se o risco, com esta modalidade de avaliação, tanto de vacuidade das respostas como de grave imprecisão já que aos adjetivos em questão correspondem conteúdos individuais que podem diferir grandemente entre si pois nada garante que o indivíduo "a" opte pela alternativa "excelente" pelas mesmas razões que o indivíduo "b”.

Para corrigir ou minimizar este tipo de problema optou-se por utilizar uma outra estratégia de avalia- ção, de corte qualitativo, solicitando-se do entrevistado não uma resposta a uma questão fechada que contenha alternativa valorativas, mas uma resposta a uma questão aberta que possibilite justamente uma descrição detalhada da sua experiência .

\section{Objetivo}

A avaliação relatada neste trabalho teve como objetivo aquilatar a satisfação dos alunos dos cursos de especialização "Capacitação e Desenvolvimento de Recursos Humanos em Saúde-CADRHU-2002, que foram oferecidos pelo convênio firmado entre a Secretaria de Estado da Saúde-SES e a Faculdade de Saúde Pública da Universidade de São Paulo-FSP/USP, com a colaboração do Ministério da Saúde- MS e da Organização Panamericana da Saúde-OPS, nos anos de 2001 e 2002.

\section{Metodologia}

Para a realização desta avaliação foi utilizada a técnica do Discurso do Sujeito Coletivo-DSC (Lefèvre e Lefèvre, 200o) que é uma proposta de organização e tabulação de dados qualitativos de natureza verbal, obtidos de depoimentos.Tendo como fundamento a teoria da Representação Social e seus pressupostos sociológicos, a proposta consiste basicamente em analisar o material verbal coletado, extraído de cada um dos depoimentos. O Discurso do Sujeito Coletivo é uma modalidade de apresentação de resultados de pesquisas qualitativas, que tem depoimentos como matéria prima, sob a forma de um ou vários discursos-síntese escritos na primeira pessoa do singular, expediente que visa expressar o pensamento de uma coletividade, como se esta coletividade fosse o emissor de um discurso.

Esta técnica consiste em selecionar, de cada resposta individual a uma questão, as Expressões-Chave, que são trechos mais significativos destas respostas. A essas Expressões Chaves correspondem Idéias Centrais que são a síntese do conteúdo discursivo manifestado nas Expressões Chave. Com o material das Expressões Chave das Idéias Centrais constróem-se discursos-síntese, na primeira pessoa do singular, que são os DSCs, onde o pensamento de um grupo ou coletividade aparece como se fosse um discurso individual. 


\section{A escolha dos sujeitos da pesquisa}

Foram ministrados quatro cursos do CADRHU, sendo que cada curso foi composto por três Módulos. Ao final de cada Módulo foi aplicado um questionário de avaliação com três questões abertas, às quais os alunos responderam por escrito e sem identificação. Considerando a grande quantidade de resultados obtidos, este trabalho aborda somente uma das questões considerada primordial. A amostra foi selecionada com $20 \%$ dos alunos de cada módulo, totalizando 78 questionários. A questão selecionada foi: " $O$ modo como este curso é dado, é, a seu ver, diferente dos outros cursos que você já participou? Fale um pouco sobre isso?".

\section{Resultados}

Serão apresentados resultados quali-quantitativos, sendo os resultados qualitativos apresentados sob a forma de DSCs, e os quantitativos sob a forma de gráfico.

Da avaliação, como um todo, foram selecionados dois DSCs considerados os mais significativos.

\section{Resultados qualitativos}

Idéias Centrais

a- A metodologia do CADRHU possibilita trocas de experiências e opiniões incentivando a participação e o debate entre os alunos.

b- A metodologia do CADRHU estimula a aprendizagem através de uma estratégia pedagógica específica que favorece o processo de reflexão e o pensamento crítico.

c- A metodologia do CADRHU possibilita atuação na realidade, no cotidiano de trabalho dos indivíduos

d- Poderia ser melhorado em alguns aspectos

e- Tem aspectos negativos que devem ser revistos

f - Outras respostas

Dsc A - A Metodologia do Cadrhu possibilita trocas de experiências e opiniões incentivando a participação e o debate entre os alunos

A metodologia é boa, diferente da tradicional, exige maturidade do grupo e, por ser problematizadora, há maior participação efetiva de todos cujas vivências ilustram as exposições e favorecem a absorção do con- teúdo. Além de valorizar as informações trazidas pelos participantes que podem opinar criticar e dar sugestões, incentiva a busca de aprimoramento; é um processo mais rico do que apenas palestras pois dá a oportunidade de conhecer e trocar idéias com diversas pessoas de diferentes realidades regionais e dos diversos componentes que formam o RH (CRH hospitais núcleos e DIR). As dinâmicas aqueceram bastante os encontros com as plenárias que foram valiosíssimas pela diversidade do grupo; essa divisão em grupo dá responsabilidade pelo andamento do curso além da oportunidade de participar e opinar.Há uma diferença em relação aos outros cursos: em nenhum momento da sua participação foi falado que aquilo que você falou está errado porque não se tem o conceito do que está certo ou errado. Até porque o certo e o errado fica de acordo com cada situação. 0 processo de discussão em grupos é importante e como os textos são complexos e com pouco tempo para leitura e interpretação a leitura em grupo facilita o entendimento de ambos. Observo que neste curso há um maior entrosamento com os monitores, mesmo estes não interferindo no desenvolvimento dos trabalhos, e todos são deixados bem à vontade na participação.

DSC B - A Metodologia do Cadrhu estimula a aprendizagem através de uma estratégia pedagógica específica que favorece o processo de reflexão e o pensamento crítico

Este método do arco é diferente dos outros cursos dos quais participei, que seguiam apostilas para o processo de dar e receber conhecimento

A maioria dos cursos dos quais participei, inclusive de outros dois na área de pós (especialização), utilizaram a pedagogia tradicional, muito embora tenham existido momentos de discussão em grupo, plenárias, etc.

Nos primeiros dias achei muito dirigido, marcado passo a passo a trajetória do curso, muito previsível. Mas observei que embora dirigido tinha um entrelaçamento muito significativo que permitia uma reflexão bem abrangente: exige mais do aluno à medida que adota como metodologia, ler, refletir, discutir em grupos vários textos, pois isso permite o debate e a reflexão sobre os assuntos tratados. E como outros cursos que participei, e que adotavam a mesma metodologia, tem como característica: proporcionar 
condições aos participantes para desenvolver consciência crítica de sua realidade e se mobilizar para provocar as transformações necessárias através do envolvimento e compromisso de todos os profissionais (atores) inseridos no contexto.

As discussões geradas a partir da realidade e a ampliação da percepção através da teoria, valoriza o conhecimento que já possuímos e o redimensiona de forma a nos tornarmos sujeitos e não somente o objeto do processo; a metodologia exige reflexão e assim desenvolve um processo de recriação, possibilitando a instrumentalização de todos os profissionais.

É um curso onde o participante aprende a aprender e os monitores exercem o papel de facilitadores, pois os monitores são mais dinâmicos e mostraram muito conhecimento ao que foi proposto, um nível muito elevado de complementação, ficando mais fácil entender as explicações. O curso incorpora plenárias após a leitura em grupo e a discussão com colegas, levando-nos às dúvidas e em seguida às respostas, ampliando nossos conhecimentos logo após as questões levantadas, facilitando o entendimento do assunto que foi discutido, e contribuindo também para a construção de novas visões críticas, pontuais, e com isto, o conhecimento inclusive histórico, cultural, político e econômico.

O curso foi coeso e o aprendizado veio devagarzinho, mas com bastante complexidade para conhecer os problemas; foi dado de uma forma bem profissional, gostei da forma que foi transmitida para a turma e pode-se perceber a construção e evolução tanto dos alunos e docentes!

Sem dúvida é uma proposta que estimula o pensamento crítico; na época que eu estudava o aluno era mais passivo, neste curso tinha que ser mais ativo, pois os textos não eram muito claros e nós, como alunos, tínhamos que localizar as respostas, passando assim de passivos para alunos ativos.

DSC C - A Metodologia do CADRHU incentiva o processo de reflexão e possibilita atuação na realidade (cotidiano de trabalho dos indivíduos)

Esse curso vem com uma metodologia diferenciada de: conceituar, problematizar através das práticas atuais; realizar um "novo modelo" abrindo possibilidades para se colocar na prática. A proposta é integrar os conceitos teóricos com a prática cotidiana. Não é possível neste modelo evoluir nas discussões sem a presença desses dois momentos. É um modelo de auto-gestão, onde as pessoas ficam muito à vontade para expressarem suas vivências, com certeza, ao romper com a dinâmica tradicional - professor x aluno, onde o professor é o "ator principal" e nós alunos nos acomodamos como "figurantes" no processo de aprendizagem.

Não houve tempo para acomodação de todo o conhecimento, mas, na minha opinião as discussões, trocas de experiências, exercícios práticos, a liga teoria/prática foram fundamentais para o sucesso do curso.

Exercícios preparatórios poderiam ser revistos, pois houve muito trabalho e pouca exploração, como na unidade 1; acho que itens que não vão ser explorados não deveriam ser pedidos. Mas hoje reconheço que esta metodologia é a mais indicada, pois através da problematização é possível visualizar a realidade vivida pelos gestores de RH, na complexa tarefa de gerenciar pessoas.

O curso visa a acumular capacidades de reconhecer e lidar com problemas concretos da realidade ou do cotidiano, ou seja, transcende o simples repasse de conhecimento e se constitui num processo de recriação do saber; pois em outros cursos nos é apenas passado a teoria sem ter a preocupação em fazer a relação com a nossa prática, enquanto que a CADRHU tem a preocupação em trazer à nossa realidade e através da teoria demonstrar o que é possível aplicar na prática.

O método visa a obtenção de uma visão crítica que é de extrema importância para a atuação profissional, faz com que o aluno seja remetido ao seu cotidiano e seja mais crítico, mostrando a nossa realidade e nos preparando para um novo sistema de trabalho na área de RH. Adorei!

\section{DSC D - Faz críticas positivas ao curso e dá sugestões}

O que ficou pesado e cansativo foram as leituras, porém, creio que não há outra forma de passarmos além, e atingir os objetivos propostos. Apesar de corrido, com o tempo cronometrado, e cansativo, no sentido de não termos tempo para entender melhor as atividades, em função do nosso dia, foi de grande valia. Gostaria que muitos dirigentes de unidades bem como alguns órgãos reguladores frequentassem "algumas" aulas.

O trabalho em grupo é importantíssimo, mesmo com o destaque ficando para aquele que tem mais facilidade para se expressar; foi muito gratificante sa- 
ber que tive o aprendizado do conteúdo passado, mas acho que poderia ser mais dinâmico, com menos leituras e mais palestras e discussões em grupo. É cansativo, mas ao final percebe-se que foi muito produtivo e saímos dele com vontade de mudar tudo. Valeu!

\section{DSC E - Tem aspectos negativos que devem ser revistos}

A metodologia aplicada é conhecida, porém o tempo para sua aplicação é muito reduzido, trazendo por vezes perda de conteúdo. Para o tempo de desenvolvimento, o número total de textos é muito elevado; dado este fato, deveriam ser solicitadas leituras prévias, sem excluir as leituras em sala de aula, assim como as leituras extra classe deveriam ser seguidas de resenhas para um melhor aproveitamento e introspecção do assunto lido. As atividades em sala de aula, com poucos expositores para trazer experiências práticas, poderiam ser racionalizadas com algumas mudanças na metodologia, com mais informações e textos mais objetivos e deveriam ser mescladas com outras diferentes, não só palestras, mas outras que produzissem maior aquisição de conhecimento.Por outro lado, o curso é muito extenso podendo ser reduzido em apenas algumas horas, substituído por dinâmicas, trabalhos, troca de experiências, etc.Tem muita didática, leituras que às vezes o torna cansativo, exaustivo, deixando até sem motivação. Também é"fechado", pois não aceita qualquer ajuste ou mudança. Além disso, discordo da dinâmica de ler textos em sala por razões como: as leituras em grupo são sofridas, tenho um ritmo de leitura diferente dos demais. as vezes quero ler mais depressa e ás vezes precisaria voltar a ler para entender o texto. Além disso achei alguns textos ári- dos demais, que em vez de facilitar, complicaram as formações de certos conceitos como a dificuldade de interpretação dos textos. Nestes casos penso que palestras talvez sejam mais eficientes. Acho também um absurdo termos que ler um texto e já produzir um trabalho em apenas uma tarde quando precisaríamos de 2 ou 3 dias para compreensão do que foi lido. Sinto que tanto esforço não valeu tanto a pena. Conceitos internalizados ficaram mais confusos no final. Poderia ser racionalizado com algumas mudanças na metodologia, com mais informações e textos mais objetivos. Na realidade para mim este curso foi bastante diferenciado dos outros cursos que já fiz pelos seguintes aspectos: foi bastante intenso, muitas horas consecutivas de curso, no final de cada módulo o aproveitamento não é adequado, em virtude do cansaço físico e mental, e por ser um curso que na forma "intensiva" pode ter apresentado algumas perdas, e o pouco tempo que vamos dedicar futuramente com as revisões particulares é que darão o complemento e o aprofundamento.

\section{DSC F - Outras respostas}

Há 24 anos no serviço público esta foi a primeira minha oportunidade de frequentar curso neste nível. Tem idéia de quanto pra mim é diferente?

É o primeiro que faço

Ele foi diferente porque tivemos poucos convidados para desenvolverem os temas com palestras ou outros recursos.

\section{Resultados quantitativos}

O gráfico abaixo representa a freqüência relativa dos diferentes tipos de DSCs.

\section{0 modo como o CADRHU é dado é diferente dos outros Cursos?}

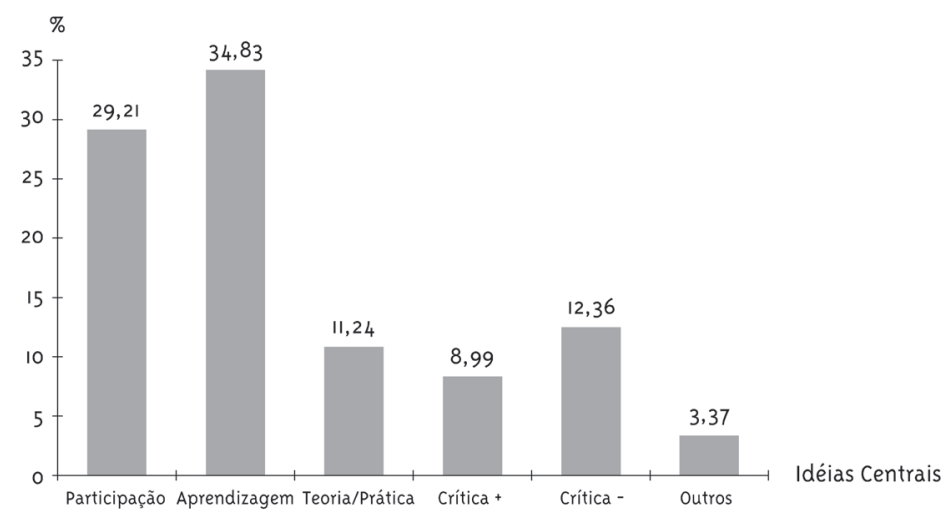


Quando tratamos de dados quantitativos no quadro do DSC, é preciso que fique claro o que está sendo objeto de quantificação

Conforme a metodologia do DSC, as Idéias Centrais dizem respeito ao que poderíamos chamar de nome do sentido do discurso professado por cada um dos sujeitos entrevistados e também por cada grupo de sujeitos que professam Idéias Centrais agrupadas num mesmo nome de sentido.

Em um trabalho sobre o DSC foi colocado que ele expressa uma Soma Qualitativa (Lefèvre \& Lefèvre, 2003) na medida em que cada depoimento ou extrato de depoimento de cada entrevistado faz parte de um determinado discurso coletivo que reúne em si depoimentos de sentidos semelhantes ou complementares.

A quantidade portanto diz respeito ao número ou percentual de pessoas, ou, mais precisamente, de respostas de pessoas, que contribuíram, com sua parte ou seu quinhão, para a constituição de um discurso entendido como um desdobramento de uma idéia em seus conteúdos e argumentos correspondentes.

Os dados quantitativos não se referem, portanto, à freqüência das Idéias Centrais mas, mais precisamente, à freqüência de respostas que contribuíram para a construção de um DSC que, por comodidade, se denominou de um determinado modo. Desta maneira, encontrou-se, que, do total de respostas à pergunta aqui analisada, $29.21 \%$ delas contribuíram para a constituição de um DSC cuja Idéia Central do tipo A sinaliza que o CADRHU foi entendido como um curso que propicia a participação e a troca de experiência entre os alunos.

Os dados quantitativos mostraram que as respostas mais freqüentes são em relação aos DSCs cujo sentido gira em torno da idéia de que a metodologia utilizada no curso propicia a participação e a aprendizagem, pois estimula a troca e amplia o processo de reflexão dos alunos.

Outro ponto que merece ser destacado é quanto a freqüência dos DSCs do tipo C (11.24\%). Este baixo percentual é bastante revelador se levarmos em conta a clientela à qual o curso se destina, gerentes de recursos humanos, onde a relação teoria-prática deve ser a essência da atividade deste profissional. Este percentual, inferior ao encontrado nos DSCs tipo A e B nos leva a concluir que o curso foi bem avaliado pelos alunos como participativo e favorecedor da aprendizagem, mas não tão bem avaliado quanto a implementação da atividade gerencial.

Devem também ser levadas em consideração as freqüências do DSC tipo D que diz respeito a aspectos positivos do curso e as do tipo E que diz respeito a aspectos negativos do curso. Note-se a freqüência superior das respostas do tipo $\mathbf{D}$ em relação às do tipo $\mathrm{E}$.

\section{Conclusões}

Pode-se dizer que, de uma maneira geral, para a questão analisada, os alunos avaliaram positivamente a pedagogia do CADRHU como favorecedora da participação (tanto entre os alunos como entre estes e os monitores) da troca de experiências, da aprendizagem e do desenvolvimento do pensamento crítico.

Mas há um discurso coletivo importante, também quantitativamente, que revela críticas bastante agudas, que precisariam ser levadas em consideração.

Outro ponto a ser destacado diz respeito à relação teoria prática, que apresenta um percentual menor de respostas do que seria esperado em se tratando de um curso com aspectos nitidamente profissionalizantes como é o caso do CADRHU.

Finalmente, deve-se destacar que a metodologia de análise quali-quantitativa (Lefèvre \& Lefèvre, 2003) proposta mostrou-se um instrumento valioso para a geração de dados primários que, na qualidade de "feedback", podem ser úteis para tanto para os proponentes do curso, quanto para seus "compradores" institucionais.

\section{Referências Bibliográficas}

BOURDIEU, P. Coisas ditas. São Paulo: Brasiliense, 1990.

BRASIL. Ministério da Saúde. Organização Panamericana da Saúde. Capacitação em desenvolvimento de recursos humanos de saúde- CADRHU. Natal: EDUFRN, 1999. p. 11. 
CORNETTA, V. K.; ARAUJO, W. G. A reorganização dos serviços de saúde no Sistema Único de Saúde e a formação de recursos humanos. Saúde em Debate, São Paulo, v.1, p.44 - 9, 1997.

DAVINI, M. C. Currículo integrado. In: SANTANA, J. P.; CASTRO, J.L. de. Capacitação em desenvolvimento de recursos humanos de saúde. Natal: EDUFRN, 1999. p. 281-289.
LEFÈVRE, F.; LEFÈVRE, A. M. C; TEIXEIRA, J. J. V. $O$ discurso do sujeito coletivo: uma nova abordagem metodológica em pesquisa qualitativa. Caxias do Sul: EDUCS, 2000.

LEFÈVRE, F.; LEFÈVRE, A. M. C. A soma qualitativa. Disponível em <http://www.fsp.usp.br/quali-saude> Acesso em: mai.2003. 